\title{
Unintended durotomy in lumbar degenerative spinal surgery: a 10-year systematic review of the literature
}

\author{
George M. Ghobrial, MD, ${ }^{1}$ Thana Theofanis, MD, ${ }^{1}$ Bruce V. Darden, MD, ${ }^{2}$ Paul Arnold, MD, ${ }^{3}$ \\ Michael G. Fehlings, MD, PhD, FRCSC, ${ }^{4}$ and James S. Harrop, MD ${ }^{1}$
}

\begin{abstract}
${ }^{1}$ Department of Neurological Surgery, Thomas Jefferson University Hospital, Philadelphia, Pennsylvania; ${ }^{2}$ Orthocarolina Spine Center, Charlotte, North Carolina; ${ }^{3}$ Department of Neurosurgery, University of Kansas, Kansas City, Kansas; and ${ }^{4}$ Department of Neurological Surgery, University of Toronto, Ontario, Canada
\end{abstract}

\begin{abstract}
OBJECT Unintended durotomy is a common occurrence during lumbar spinal surgery, particularly in surgery for degenerative spinal conditions, with the reported incidence rate ranging from $0.3 \%$ to $35 \%$. The authors performed a systematic literature review on unintended lumbar spine durotomy, specifically aiming to identify the incidence of durotomy during spinal surgery for lumbar degenerative conditions. In addition, the authors analyzed the incidence of durotomy when minimally invasive surgical approaches were used as compared with that following a traditional midline open approach.

METHODS A MEDLINE search using the term "lumbar durotomy" (under the 2015 medical subject heading [MeSH] "cerebrospinal fluid leak") was conducted on May 13, 2015, for English-language medical literature published in the period from January 1, 2005, to May 13, 2015. The resulting papers were categorized into 3 groups: 1) those that evaluated unintended durotomy rates during open-approach lumbar spinal surgery, 2) those that evaluated unintended durotomy rates during minimally invasive spine surgery (MISS), and 3) those that evaluated durotomy rates in comparable cohorts undergoing MISS versus open-approach lumbar procedures for similar lumbar pathology.

RESULTS The MEDLINE search yielded 116 results. A review of titles produced 22 potentially relevant studies that described open surgical procedures. After a thorough review of individual papers, 19 studies (comprising 15,965 patients) pertaining to durotomy rates during open-approach lumbar surgery were included for analysis. Using the Oxford Centre for Evidence-Based Medicine (CEBM) ranking criteria, there were 7 Level 3 prospective studies and 12 Level 4 retrospective studies. In addition, the authors also included 6 studies (with a total of 1334 patients) that detailed rates of durotomy during minimally invasive surgery for lumbar degenerative disease. In the MISS analysis, there were 2 prospective and 4 retrospective studies. Finally, the authors included 5 studies (with a total of 1364 patients) that directly compared durotomy rates during open-approach versus minimally invasive procedures. Studies of open-approach surgery for lumbar degenerative disease reported a total of 1031 durotomies across all procedures, for an overall durotomy rate of $8.11 \%$ (range $2 \%-20 \%$ ). Prospectively designed studies reported a higher rate of durotomy than retrospective studies $(9.57 \%$ vs $4.32 \%, p=0.05)$. Selected MISS studies reported a total of 93 durotomies for a combined durotomy rate of $6.78 \%$. In studies of matched cohorts comparing open-approach surgery with MISS, the durotomy rates were $7.20 \%$ (34 durotomies) and $7.02 \%$ (68), respectively, which were not significantly different.
\end{abstract}

CONCLUSIONS Spinal surgery for lumbar degenerative disease carries a significant rate of unintended durotomy, regardless of the surgical approach selected by the surgeon. Interpretation of unintended durotomy rates for lumbar surgery is limited by a lack of prospective and cohort-matched controlled studies.

http://thejns.org/doi/abs/10.3171/2015.7.FOCUS15266

KEY WORDS lumbar spine; durotomy; cerebrospinal fluid leak; complications; trauma; thoracolumbar

$\mathrm{U}$ NINTENDED durotomy is a common occurrence during lumbar spinal surgery for degenerative spinal indications, and rates of durotomy can range from as low as $0.3 \%$ in lumbar discectomy ${ }^{26}$ to $35 \%$ in an isolated study involving instrumented fusions for lumbosacral spondylolisthesis ${ }^{33}$ The overall incidence is reported to be approximately $17 \%$ across all spinal indications and regions. ${ }^{1}$ A number of factors have been cited for increasing risk of durotomy during lumbar surgery, including revision surgery, ${ }^{14,43}$ lumbar degenerative indications relative to op-

ABBREVIATIONS BMI = body mass index; MISS = minimally invasive spine surgery; PLIF = posterior lumbar interbody fusion; TLIF = transforaminal lumbar interbody fusion. 
erating at the cervical or thoracic level,,${ }^{20}$ diabetes,${ }^{31}$ age,${ }^{17}$ obesity, and surgical-invasiveness score. ${ }^{3,6,20,43}$ Moreover, some studies suggest that unintended durotomies will occur regardless of the surgeon's prior experience. ${ }^{31}$

Unintended durotomy can result in neurological deficit because of the proximity of the neural tissue and the dural sleeve. ${ }^{43}$ However, neurological deficit does not always occur, as Wang et al. noted no instances of neural damage resulting from unintended durotomy during lumbar spinal surgery in a large retrospective study of 641 patients. ${ }^{43}$ Several comorbidities have been reported to occur after an unintended durotomy including spinal headaches, ${ }^{34}$ pseudomeningocoele, ${ }^{18}$ meningitis, ${ }^{24}$ and nerve root entrapment resulting in intractable pain. ${ }^{1}$ Despite these morbidities, the occurrence of an unintended durotomy has been shown in prospective studies to have no significant impact on patient functional outcomes, postoperative complications, and pain ${ }^{1}$ and that persistent CSF leaks are manageable with good results. ${ }^{43}$

"Open" or traditional surgical approaches rely on a traditional midline subperiosteal dissection, with resulting elevation and retraction of the paraspinal musculature to expose the posterior elements of the spine. A metaanalysis performed by Zhang and colleagues reported that variations in open approaches to the posterior lumbar interbody space can influence the rate of unintended durotomy. ${ }^{46}$ Specifically, transforaminal lumbar interbody fusion (TLIF) procedures had a significantly lower durotomy rate as compared with posterior lumbar interbody fusion (PLIF), which is a more medial approach. ${ }^{46}$ However, one drawback to making interpretations based on literature reviews is that lumbar surgical approaches and complication rates are evaluated based on a heterogenic population and multiple studies; there is a lack of randomized clinical trials and thus a high reliance on retrospective studies. ${ }^{46}$

Minimally invasive spine surgery (MISS) refers to a modification of the traditional approach that minimizes muscle manipulation, soft tissue dissection, pain, and blood loss. ${ }^{27}$ The confusion between MISS and open spinal surgery is that these divisions have the same aforementioned overarching goals and that "minimally" or "less invasive" surgery can be described as a philosophy more than a specific set of procedures. In general, percutaneous, endoscopic, and keyhole approaches using trocars or tubular retractors often involve smaller incisions from an approach lateral to the midline in an attempt to minimize trauma, retraction, and devascularization of the posterior soft tissues, which can be associated with pain, blood loss, narcotics use, and prolonged hospital stays.

The aim of this study was to analyze unintended durotomy in the medical literature in order to clarify the incidence of durotomy during lumbar spinal surgery and to compare the rates of durotomy in studies with MISS and open-approach cohorts.

\section{Methods}

A MEDLINE search using the term "lumbar durotomy" (under the medical subject heading [MeSH] "cerebrospinal fluid leak") was conducted on May 13, 2015, to evaluate the English-language medical literature for pertinent studies relating to unintended durotomy that were published in the period from January 1, 2005, to May 13, 2015. Two authors (G.M.G. and T.T.) reviewed the titles of papers that were returned in the initial search to determine if the papers were pertinent to a durotomy encountered during lumbar spinal surgery for common degenerative spinal indications. Articles that were pertinent and those that were unclear in the initial search were included for further review. After a detailed review of the abstract, individual papers were evaluated for final inclusion in the data analysis, and the bibliographies were collected.

\section{Inclusion Criteria}

The reviewed literature included retrospective and prospective studies whose levels of evidence were classified as Levels 1-4 according to the Oxford Centre for Evidence-Based Medicine (CEBM) ranking criteria. Relevant papers were selected for inclusion in the systematic review based on a detailed analysis of the title, abstract, and body text.

\section{Exclusion Criteria}

Meta-analyses, systematic reviews, editorials, case reports, and case series with less than 10 patients were excluded. Case series not entirely composed of patients undergoing lumbar spinal surgery were also excluded. Lumbar surgery indications other than common degenerative indications were excluded, including spinal neoplasm surgery, scoliosis, and other deformity-correction procedures. In addition, we excluded laboratory or animal research studies, non-English publications, commentaries, descriptive studies, technical notes, and those articles deemed irrelevant.

\section{Outcome, Review, and Analysis by Surgical Approach}

Papers were categorized by surgical procedure into 3 discrete groups for further analysis: 1) surgical series involving only open-approach lumbar procedures, 2) studies involving MISS only, and 3) studies of comparable cohorts that underwent open spine surgery or MISS for similar degenerative lumbar pathology. The primary outcome was unintended durotomy during lumbar spine surgery. Study analysis was conducted in accordance with the Preferred Reporting Items for Systematic Reviews and Meta-Analyses (PRISMA) guidelines. ${ }^{12}$ A Student ttest was used to compare rates of durotomy between open spine surgery and MISS using a statistical software analysis package designed for use with Microsoft Excel 2010, version 14.0.7149.5000.

\section{Definitions of MISS}

The procedures for minimally invasive transforaminal lumbar interbody fusion (MIS-TLIF), minimally invasive posterior lumbar interbody fusion (MIS-PLIF), and discectomy were performed according to commonly described lumbar decompression and fusion techniques previously described, notably by Foley and colleagues. ${ }^{11,16}$ The aforementioned procedures were classified as minimally invasive if they involved a paramedian incision and 


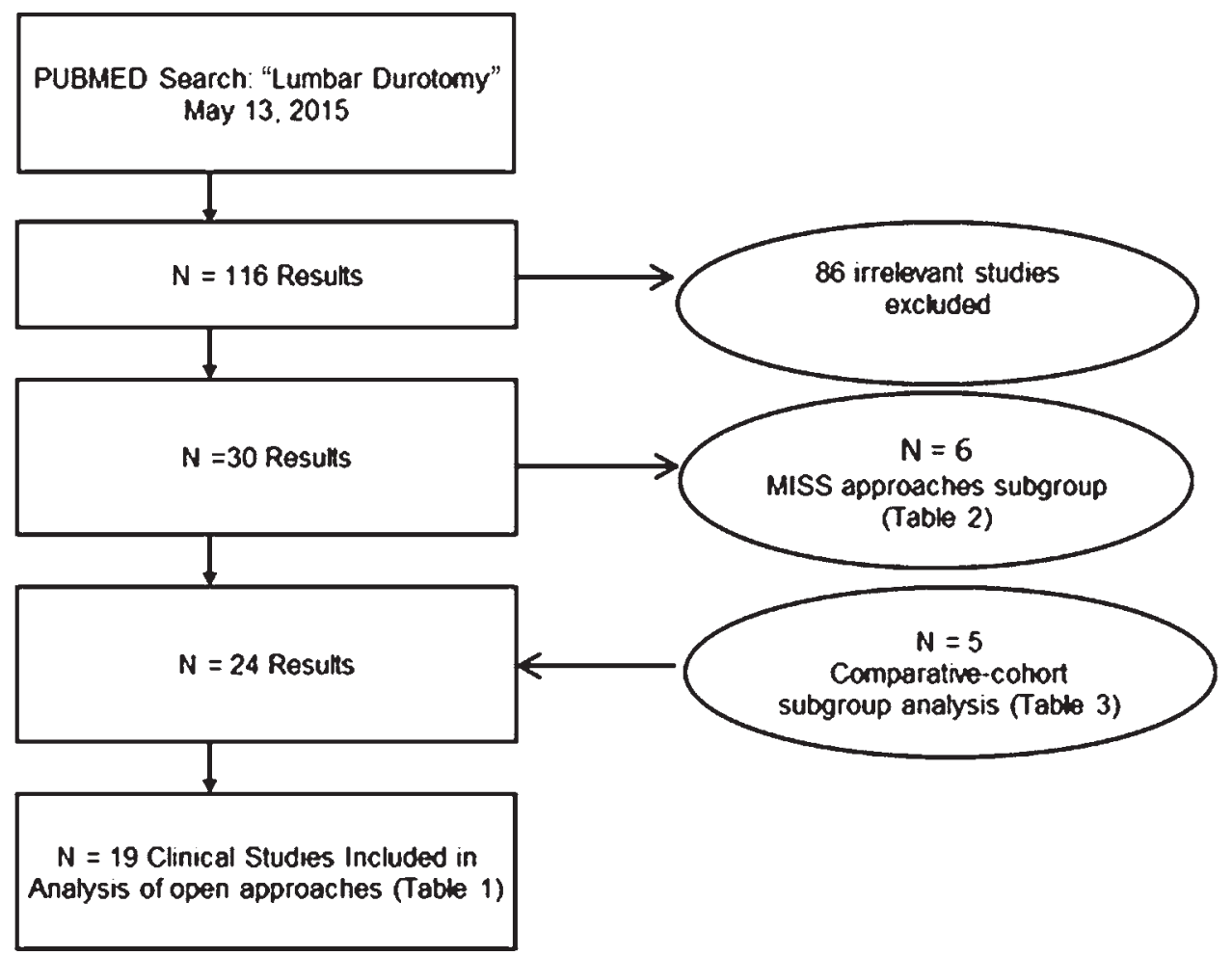

FIG. 1. Flow diagram of study selection.

tubular or multiple-blade retractor systems with the intention of limiting approach-related morbidity.

\section{Results}

An advanced MEDLINE search for lumbar durotomy yielded 116 results. After reviewing the paper titles and utilizing our inclusion and exclusion criteria, 22 potentially relevant studies on open surgical procedures remained for detailed analysis. This number was further refined to 19 studies (comprising 15,965 patients) after we limited our analysis to those studies focused on open approaches for lumber surgery (Fig. 1). In total, our studies for openapproach surgery consisted of 7 prospective studies and 12 retrospective studies (Table 1 ).

Six studies (comprising 1334 patients) were analyzed for durotomy occurrence during minimally invasive lumbar surgery for degenerative disease (Table 2). There were 2 prospective and 4 retrospective studies. Finally, 5 studies (comprising 1364 patients) were analyzed for direct comparison of durotomy rates in matched cohorts of patients who underwent open versus minimally invasive procedures for similar lumbar pathology (Table 3).

\section{Durotomy Rate}

Studies involving open surgical procedures performed for lumbar degenerative disease reported a total of 1031 durotomies across all procedures for an overall durotomy incidence of $8.11 \%$ (range 2\%-20\%). Prospectively designed studies reported a higher durotomy rate than retrospective studies $(9.57 \%$ vs $4.32 \%, p=0.05)$. Studies se- lected for analysis of MISSs included a total of 93 durotomies for an overall durotomy rate of $6.78 \%$. In studies of matched cohorts comparing open surgery and minimally invasive approaches, the durotomy rates were $7.20 \%$ (34 durotomies) and $7.02 \%$ (68), respectively, which were not significantly different.

\section{Discussion}

The frequency of lumbar surgery for the treatment of patients with degenerative spinal indications is increasing, and studies of the Nationwide Inpatient Sample have shown that the number of procedures, ${ }^{45}$ specifically for lumbar degenerative indications, has doubled in the last decade. With this increased volume of lumbar operations and the increased fusion rate, the impact of durotomy recognition and management becomes increasingly important.

\section{Open Lumbar Procedures}

The reported rates of durotomy in studies of openapproach procedures for lumbar degenerative conditions were not insignificant; a total of 1031 durotomies were reported, for a rate of $8.11 \%$ (range 2\%-20\%; Table 1). Surgical invasiveness and manipulation of the dura have been reported as a general predictors ${ }^{3}$ of durotomy and appeared to correlate with overall durotomy rates. One retrospective study by Sofianos et al. analyzed complications of lateral lumbar interbody fusions, which are performed away from the dura, and found a $2 \%$ durotomy rate. ${ }^{39}$ The durotomy rates in studies entirely composed 
TABLE 1. Selected studies for analysis of open-approach procedures

\begin{tabular}{|c|c|c|c|c|c|c|}
\hline Authors \& Year & Type of Study & $\begin{array}{c}\text { No. of } \\
\text { Patients }\end{array}$ & Lumbar Procedure (n) & $\begin{array}{l}\text { Incidence of } \\
\text { Durotomy (n) }\end{array}$ & $\begin{array}{l}\text { Durotomy } \\
\text { Rate }\end{array}$ & Risk Factor Identified \\
\hline Smorgick et al., 2015 & Prospective cohort & 523 & Discectomy (131), laminectomy (392) & 55 & $10.5 \%$ & Prior lumbar surgery \\
\hline Desai et al., 2015 & Prospective cohort & 439 & Laminectomy $+/$ - fusion & 37 & $9 \%$ & NA \\
\hline Chen et al., 2015 & Retrospective & 2184 & Unspecified & 101 & $4.62 \%$ & $\begin{array}{l}\text { Prior lumbar surgery, } \\
\text { older age }\end{array}$ \\
\hline Bydon et al., 2015 & Retrospective & 327 & Lumbar posterolateral fusion & 17 & $5.19 \%$ & NA \\
\hline Blecher et al., 2014 & Retrospective & 1235 & Unspecified & 84 & $6.8 \%$ & NA \\
\hline Adogwa et al., 2014 & Prospective & 1741 & Lumbar fusion & 70 & $4.0 \%$ & NA \\
\hline Low et al., 2013 & Retrospective & 889 & Unspecified & 61 & $6.8 \%$ & NA \\
\hline Takashi et al., 2013 & Retrospective & 1014 & Multimodal & 40 & $4.0 \%$ & $\begin{array}{l}\text { Female sex, older } \\
\text { age, degen spondy, } \\
\text { juxtafacet cysts }\end{array}$ \\
\hline Desai et al., 2013 & Retrospective & 793 & Lumbar laminectomy $+/-$ fusion & 78 & $9.8 \%$ & NA \\
\hline Desai et al., 2012 & Prospective & 792 & First time lumbar discectomy & 25 & $3.0 \%$ & NA \\
\hline Baker et al., 2012 & Prospective & 1745 & Multimodal & 161 & $10.0 \%$ & Revision surgery \\
\hline Tormenti et al., 2012 & Retrospective & 531 & TLIF & 76 & $14.3 \%$ & $\begin{array}{l}\text { Revision surgery, } \\
\text { multilevel TLIF }\end{array}$ \\
\hline Desai et al., 2013 & Prospective & 389 & Decompressive laminectomy & 41 & $10.5 \%$ & NA \\
\hline Sofianos et al., 2012 & Retrospective & 45 & Lateral transpsoas approach & 1 & $2.0 \%$ & NA \\
\hline Guerin et al., 2012 & Retrospective & 1326 & Multimodal & 48 & $3.61 \%$ & NA \\
\hline Mehta et al., 2011 & Retrospective & 119 & PLIF (76), TLIF (43) & 17 & $14.2 \%$ & PLIF \\
\hline Kalevski et al., 2010 & Retrospective & 553 & Multimodal & 70 & $12.6 \%$ & $\begin{array}{l}\text { Revision surgery, } \\
\text { spinal trauma }\end{array}$ \\
\hline $\begin{array}{l}\text { Rodriguez-Olaverri et } \\
\text { al., } 2008\end{array}$ & Prospective & 40 & $\begin{array}{l}\text { Unilateral TLIF, transvertebral screw } \\
\text { fixation }\end{array}$ & 8 & $20.0 \%$ & NA \\
\hline Saxler et al., 2005 & Retrospective & 1280 & Lumbar discectomy & 41 & $3.2 \%$ & NA \\
\hline
\end{tabular}

degen spondy = degenerative spondylosis; NA = not applicable.

of open-approach decompression without fusion ranged from $3.2 \%$ with discectomy alone ${ }^{36}$ to $10.5 \%$ in a series by Smorgick et al. in which approximately one-third of the patients had undergone prior spinal surgery. The durotomy incidence in a group of patients who underwent revision surgery was $25 \%$ (29 of 116) and was not associated with the years of experience of the surgeon performing the procedure. ${ }^{38}$ Studies entirely composed of interbody fusion procedures, such as those conducted by Mehta et al. ${ }^{28}$ and Tormenti et al., ${ }^{42}$ reported higher durotomy rates of
$14.2 \%$ and $14.3 \%$, respectively. The highest durotomy rate, $20 \%$, was reported in a non-cohort-matched prospective study by Rodriguez-Olaverri and colleagues in which the authors evaluated clinical and radiographic outcomes of instrumented fusion for high-grade spondylolisthesis. ${ }^{33}$

\section{MISS Approaches}

Minimally invasive approaches had an overall durotomy rate of $6.78 \%$; this rate was calculated using the 6

TABLE 2. Reported durotomies for minimally invasive approaches for degenerative lumbar spinal surgery

\begin{tabular}{llrlrrr}
\hline \multicolumn{1}{c}{ Authors \& Year } & \multicolumn{1}{c}{ Study Type } & $\begin{array}{c}\text { No. of } \\
\text { Patients }\end{array}$ & $\begin{array}{c}\text { Minimally Invasive } \\
\text { Procedure }\end{array}$ & $\begin{array}{c}\text { Incidence of } \\
\text { Durotomy (n) }\end{array}$ & $\begin{array}{c}\text { Rate of } \\
\text { Durotomy }\end{array}$ & $\begin{array}{c}\text { Predictor of } \\
\text { Durotomy }\end{array}$ \\
\hline Wong et al., 2014 & Retrospective & 513 & MIS-TLIF & 26 & $5.1 \%$ & Multilevel MIS-TLIF \\
\hline Tender \& Serban, 2014 & Retrospective & 60 & $\begin{array}{c}\text { MIS-TLIF (tubular vs screw- } \\
\text { based retractor technique) }\end{array}$ & 3 & $5.0 \%$ & NA \\
\hline Lee et al., 2012 & Prospective cohort & 90 & Single-level MIS-TLIF & 1 & $1.1 \%$ & NA \\
\hline Nandyala et al., 2014 & Prospective cohort & 65 & Single-level MIS-TLIF & 4 & $6.1 \%$ & NA \\
\hline Ruban \& O'Toole, 2011 & Retrospective & 563 & Multimodal MISS & 53 & $9.4 \%$ & NA \\
\hline Selznick et al., 2009 & Retrospective & 43 & MIS-TLIF, MIS-PLIF & 6 & $14.0 \%$ & Revision surgery \\
\hline
\end{tabular}


TABLE 3. Reported durotomy rates in selected studies using matched cohorts to compare open versus MISS techniques for lumbar degenerative disease

\begin{tabular}{|c|c|c|c|c|c|c|c|c|c|}
\hline \multirow{2}{*}{$\begin{array}{l}\text { Authors \& } \\
\quad \text { Year }\end{array}$} & \multirow[b]{2}{*}{ Study Type } & \multirow{2}{*}{$\begin{array}{l}\text { No. of } \\
\text { Patients }\end{array}$} & \multirow{2}{*}{$\begin{array}{l}\text { Minimally Invasive } \\
\text { Procedures (n) }\end{array}$} & \multirow{2}{*}{$\begin{array}{c}\text { Open } \\
\text { Procedures (n) }\end{array}$} & \multicolumn{2}{|c|}{ No. of Durotomies } & \multicolumn{2}{|c|}{$\%$ Durotomies } & \multirow{2}{*}{$\begin{array}{l}\text { Predictor of } \\
\text { Durotomy }\end{array}$} \\
\hline & & & & & MISS & Open & MISS & Open & \\
\hline $\begin{array}{l}\text { Kogias et al., } \\
2015\end{array}$ & $\begin{array}{l}\text { Retrospective } \\
\text { case-control }\end{array}$ & 135 & Tubular discectomy (53) & $\begin{array}{l}\text { Open discectomy } \\
(82)\end{array}$ & 9 & 16 & $17.0 \%$ & $19.5 \%$ & NA \\
\hline $\begin{array}{l}\text { Wong et al., } \\
2014\end{array}$ & Retrospective & 863 & $\begin{array}{l}\text { Discectomy, foraminoto- } \\
\text { my, laminectomy (320) }\end{array}$ & $\begin{array}{l}\text { Open version of } \\
\text { MISS group (543) }\end{array}$ & 15 & 49 & $4.7 \%$ & $9.0 \%$ & Open surgery \\
\hline $\begin{array}{l}\text { Ang et al., } \\
2015\end{array}$ & Retrospective & 113 & Lumbar laminotomy (83) & $\begin{array}{l}\text { Open version of } \\
\text { MISS group (30) }\end{array}$ & 3 & 0 & $3.6 \%$ & $0.0 \%$ & NA \\
\hline $\begin{array}{l}\text { Lee et al., } \\
\qquad 2012\end{array}$ & Retrospective & 144 & $\begin{array}{l}\text { Single-level MIS-TLIF } \\
\quad(72)\end{array}$ & $\begin{array}{l}\text { Open version of } \\
\text { MISS group (72) }\end{array}$ & 1 & 0 & $1.4 \%$ & $0.0 \%$ & NA \\
\hline $\begin{array}{l}\text { Lee et al., } \\
2011\end{array}$ & Retrospective & 109 & Tubular discectomy (64) & $\begin{array}{l}\text { Open discectomy } \\
\text { (45) }\end{array}$ & 6 & 3 & $9.3 \%$ & $6.6 \%$ & NA \\
\hline
\end{tabular}

identified studies that primarily involved interbody fusion procedures, with the exception of 1 multimodal retrospective study by Ruban and O'Toole. ${ }^{35}$ The durotomy rates were less interpretable in the lumbar MISS series because of limited numbers of patients and an undefined definition of durotomy. Thus, the reported incidence varied widely, ranging from $1 \%$ to $14 \% .^{22,37}$ Selznick and colleagues ${ }^{37}$ reported a $14 \%$ durotomy rate in their series containing 43 MIS-TLIF and MIS-PLIF procedures. Although their study was limited by its retrospective design, no major complications attributed to these durotomies were reported, and nerve root injury, infection, and the need for any revision procedure to convert to open surgery were not described. ${ }^{37}$ Almost all durotomies needed to be repaired by converting to an open approach.

\section{Cohort-Matched Open Surgery Versus MISS Approaches}

Matched-cohort studies published in the past 10 years were evaluated in an attempt to find more meaningful comparative data on durotomy rates in patients who underwent either open-approach or MISS procedures (Table $3)$. Five retrospective studies were selected. The durotomy rates did not significantly differ between MISS and open surgery cohorts, with overall rates of $7.20 \%$ (34 durotomies) and $7.02 \%$ (68), respectively. However, the total number of patients (1364) was limited, and background patient characteristics, such as body mass index (BMI), were not well matched in all studies, which can significantly impact durotomy rates. ${ }^{3}$ Wong and colleagues, who evaluated 863 patients undergoing 1- or 2-level decompression in a retrospective matched-cohort study, noted a significantly higher durotomy rate in the open surgery group versus the MISS group ( $9 \%$ vs $4.7 \%, \mathrm{p}=0.01) .{ }^{44}$ To date, only 1 other cohort-matched study revealed a higher rate of durotomy in the open surgery category. ${ }^{32}$ In addition to the retrospective design, one major confounder in the Wong et al. study was the significantly higher percentage of revision surgery patients in the open surgery cohort ( $21.7 \%$ vs $16.0 \%, \mathrm{p}=0.05)$.

Numerous obstacles limit the interpretation of matchedcohort studies when comparing durotomy rates. A study by Wong et al. was performed in an institution where $37 \%$ of all decompressions over a 5-year period (320 of 863) were MISS procedures. ${ }^{44}$ This high volume of MISS procedures speaks to the technical proficiency of the surgeons contributing to this series, which in part could explain the lower durotomy rate. Furthermore, the standard selection markers for minimally invasive procedures favor choosing patients who have a relatively lower risk for durotomies, i.e., younger, undergoing nonrevision surgery, less degenerative spondylosis, and lower BMI. Moreover, studies evaluating complication rates of MISS over time have not yet revealed a significant difference in the durotomy rates, although a significant decrease in other intraoperative parameters have been observed. ${ }^{29}$

\section{Retrospective Versus Prospective Design}

Study methodology remains a significant factor in measuring complication rates. Of the 19 open-approach studies selected, 12 were retrospective and 7 were prospective. Of the 7 prospective studies, only 5 were cohort-matched. The prospectively designed studies for open surgery procedures had over twice the durotomy rate $(9.57 \%)$ as compared with retrospective studies (4.32\%). The mix of procedures in the prospective patient category was well distributed between decompression alone and fusion, but other risk factors for durotomy such as number of decompression levels treated, patient age, obesity, and revision surgery were not tracked in all studies (Table 4). Despite this, the probable explanation for the lower durotomy rate in the retrospec-

TABLE 4. Summary of selected studies

\begin{tabular}{|c|c|c|c|}
\hline Study Design & $\begin{array}{l}\text { Total No. } \\
\text { of Patients }\end{array}$ & $\begin{array}{c}\text { Durotomy } \\
\text { Rate }\end{array}$ & $\begin{array}{c}p \\
\text { Value }\end{array}$ \\
\hline Retrospective & 10,296 & $4.32 \%$ & 0.05 \\
\hline Prospective & 5669 & $9.57 \%$ & \\
\hline \multicolumn{4}{|l|}{ MISS vs open surgery } \\
\hline MISS cohort & 592 & $7.2 \%$ & \multirow[t]{2}{*}{0.92} \\
\hline Open cohort & 772 & $7.02 \%$ & \\
\hline \multicolumn{4}{|c|}{ MIS: retrospective vs prospective } \\
\hline Retrospective & 1179 & $8.38 \%$ & \multirow[t]{2}{*}{0.26} \\
\hline Prospective & 155 & $3.60 \%$ & \\
\hline
\end{tabular}


tive series is the inadequate study design that does not capture all complications. In a systematic review of posterior spine surgery approaches, Nasser and colleagues reviewed 105 articles with a total of 79,471 patients..$^{30}$ When evaluating posterior thoracolumbar procedures, they found a significantly higher complication rate in the prospective study group $(20.4 \%$ vs $17.5 \%, p<0.0001)$, which they attributed to data collection methodology.

\section{Conclusions}

Spinal surgery for lumbar degenerative disease carries a significant rate of unintended durotomy, regardless of whether the surgeon selects an open or minimally invasive surgical approach. Interpretation of unintended durotomy rates for lumbar surgery is limited because of a lack of prospective and cohort-matched controlled studies.

\section{References}

1. Adogwa O, Huang MI, Thompson PM, Darlington T, Cheng JS, Gokaslan ZL, et al: No difference in postoperative complications, pain, and functional outcomes up to 2 years after incidental durotomy in lumbar spinal fusion: a prospective, multi-institutional, propensity-matched analysis of 1,741 patients. Spine J 14:1828-1834, 2014

2. Ang CL, Phak-Boon Tow B, Fook S, Guo CM, Chen JL, Yue WM, et al: Minimally invasive compared with open lumbar laminotomy: no functional benefits at 6 or 24 months after surgery. Spine J 15:1705-1712, 2015

3. Baker GA, Cizik AM, Bransford RJ, Bellabarba C, Konodi MA, Chapman JR, et al: Risk factors for unintended durotomy during spine surgery: a multivariate analysis. Spine J 12:121-126, 2012

4. Blecher R, Anekstein Y, Mirovsky Y: Incidental dural tears during lumbar spine surgery: a retrospective case study of 84 degenerative lumbar spine patients. Asian Spine J 8:639645, 2014

5. Bydon M, De la Garza-Ramos R, Abt NB, Macki M, Sciubba DM, Wolinsky JP, et al: Durotomy is associated with pseudoarthrosis following lumbar fusion. J Clin Neurosci 22:544-548, 2015

6. Cammisa FP Jr, Girardi FP, Sangani PK, Parvataneni HK, Cadag S, Sandhu HS: Incidental durotomy in spine surgery. Spine (Phila Pa 1976) 25:2663-2667, 2000

7. Chen Z, Shao P, Sun Q, Zhao D: Risk factors for incidental durotomy during lumbar surgery: a retrospective study by multivariate analysis. Clin Neurol Neurosurg 130:101-104, 2015

8. Desai A, Ball PA, Bekelis K, Lurie J, Mirza SK, Tosteson TD, et al: SPORT: Does incidental durotomy affect longterm outcomes in cases of spinal stenosis? Neurosurgery 76 (Suppl 1):S57-S63, 2015

9. Desai A, Bekelis K, Ball PA, Lurie J, Mirza SK, Tosteson TD, et al: Spine patient outcomes research trial: do outcomes vary across centers for surgery for lumbar disc herniation? Neurosurgery 71:833-842, 2012

10. Desai A, Bekelis K, Ball PA, Lurie J, Mirza SK, Tosteson TD, et al: Variation in outcomes across centers after surgery for lumbar stenosis and degenerative spondylolisthesis in the spine patient outcomes research trial. Spine (Phila Pa 1976) 38:678-691, 2013

11. Foley KT, Holly LT, Schwender JD: Minimally invasive lumbar fusion. Spine (Phila Pa 1976) 28 (15 Suppl):S26-S35, 2003

12. Foster RL: Reporting guidelines: CONSORT, PRISMA, and SQUIRE. J Spec Pediatr Nurs 17:1-2, 2012
13. Guerin P, El Fegoun AB, Obeid I, Gille O, Lelong L, Luc S, et al: Incidental durotomy during spine surgery: incidence, management and complications. A retrospective review. Injury 43:397-401, 2012

14. Hannallah D, Lee J, Khan M, Donaldson WF, Kang JD: Cerebrospinal fluid leaks following cervical spine surgery. J Bone Joint Surg Am 90:1101-1105, 2008

15. Heneghan C: EBM resources on the new CEBM website. Evid Based Med 14:67, 2009

16. Holly LT, Schwender JD, Rouben DP, Foley KT: Minimally invasive transforaminal lumbar interbody fusion: indications, technique, and complications. Neurosurg Focus 20(3):E6, 2006

17. Jankowitz BT, Atteberry DS, Gerszten PC, Karausky P, Cheng BC, Faught R, et al: Effect of fibrin glue on the prevention of persistent cerebral spinal fluid leakage after incidental durotomy during lumbar spinal surgery. Eur Spine J 18:1169-1174, 2009

18. Kaar GF, Briggs M, Bashir SH: Thecal repair in post-surgical pseudomeningocoele. Br J Neurosurg 8:703-707, 1994

19. Kalevski SK, Peev NA, Haritonov DG: Incidental dural tears in lumbar decompressive surgery: Incidence, causes, treatment, results. Asian J Neurosurg 5:54-59, 2010

20. Khan MH, Rihn J, Steele G, Davis R, Donaldson WF III, Kang JD, et al: Postoperative management protocol for incidental dural tears during degenerative lumbar spine surgery: a review of 3,183 consecutive degenerative lumbar cases. Spine (Phila Pa 1976) 31:2609-2613, 2006

21. Kogias E, Klingler JH, Franco Jimenez P, Vasilikos I, Sircar $\mathrm{R}$, Scholz C, et al: Incidental durotomy in open versus tubular revision microdiscectomy: a retrospective controlled study on incidence, management and outcome. J Spinal Disord Tech [epub ahead of print], 2015

22. Lee KH, Yue WM, Yeo W, Soeharno H, Tan SB: Clinical and radiological outcomes of open versus minimally invasive transforaminal lumbar interbody fusion. Eur Spine $\mathbf{J}$ 21:2265-2270, 2012

23. Lee P, Liu JC, Fessler RG: Perioperative results following open and minimally invasive single-level lumbar discectomy. J Clin Neurosci 18:1667-1670, 2011

24. Lin TY, Chen WJ, Hsieh MK, Lu ML, Tsai TT, Lai PL, et al: Postoperative meningitis after spinal surgery: a review of 21 cases from 20,178 patients. BMC Infect Dis 14:220, 2014

25. Low JC, von Niederhäusern B, Rutherford SA, King AT: Pilot study of perioperative accidental durotomy: does the period of postoperative bed rest reduce the incidence of complication? Br J Neurosurg 27:800-802, 2013

26. Mayfield FH, Kurokawa K: Watertight closure of spinal dura mater. Technical note. J Neurosurg 43:639-640, 1975

27. McAfee PC, Garfin SR, Rodgers WB, Allen RT, Phillips F, Kim C: An attempt at clinically defining and assessing minimally invasive surgery compared with traditional "open" spinal surgery. SAS J 5:125-130, 2011

28. Mehta VA, McGirt MJ, Garcés Ambrossi GL, Parker SL, Sciubba DM, Bydon A, et al: Trans-foraminal versus posterior lumbar interbody fusion: comparison of surgical morbidity. Neurol Res 33:38-42, 2011

29. Nandyala SV, Fineberg SJ, Pelton M, Singh K: Minimally invasive transforaminal lumbar interbody fusion: one surgeon's learning curve. Spine J 14:1460-1465, 2014

30. Nasser R, Yadla S, Maltenfort MG, Harrop JS, Anderson DG, Vaccaro AR, et al: Complications in spine surgery. J Neurosurg Spine 13:144-157, 2010

31. Pechlivanis I, Kuebler M, Harders A, Schmieder K: Perioperative complication rate of lumbar disc microsurgery depending on the surgeon's level of training. Cent Eur Neurosurg 70:137-142, 2009

32. Rahman M, Summers LE, Richter B, Mimran RI, Jacob RP: Comparison of techniques for decompressive lumbar lami- 
nectomy: the minimally invasive versus the "classic" open approach. Minim Invasive Neurosurg 51:100-105, 2008

33. Rodriguez-Olaverri JC, Zimick NC, Merola A, Vicente J, Rodriguez J, Tabuenca A, et al: Comparing the clinical and radiological outcomes of pedicular transvertebral screw fixation of the lumbosacral spine in spondylolisthesis versus unilateral transforaminal lumbar interbody fusion (TLIF) with posterior fixation using anterior cages. Spine (Phila Pa 1976) 33:1977-1981, 2008

34. Rozen T, Swidan S, Hamel R, Saper J: Trendelenburg position: a tool to screen for the presence of a low CSF pressure syndrome in daily headache patients. Headache 48:13661371,2008

35. Ruban D, O'Toole JE: Management of incidental durotomy in minimally invasive spine surgery. Neurosurg Focus 31(4):E15, 2011

36. Saxler G, Krämer J, Barden B, Kurt A, Pförtner J, Bernsmann K: The long-term clinical sequelae of incidental durotomy in lumbar disc surgery. Spine (Phila Pa 1976) 30:2298-2302, 2005

37. Selznick LA, Shamji MF, Isaacs RE: Minimally invasive interbody fusion for revision lumbar surgery: technical feasibility and safety. J Spinal Disord Tech 22:207-213, 2009

38. Smorgick Y, Baker KC, Herkowitz H, Montgomery D, Badve SA, Bachison C, et al: Predisposing factors for dural tear in patients undergoing lumbar spine surgery. J Neurosurg Spine 22:483-486, 2015

39. Sofianos DA, Briseño MR, Abrams J, Patel AA: Complications of the lateral transpsoas approach for lumbar interbody arthrodesis: a case series and literature review. Clin Orthop Relat Res 470:1621-1632, 2012

40. Takahashi Y, Sato T, Hyodo H, Kawamata T, Takahashi E, Miyatake N, et al: Incidental durotomy during lumbar spine surgery: risk factors and anatomic locations: clinical article. J Neurosurg Spine 18:165-169, 2013

41. Tender GC, Serban D: Minimally invasive transforaminal lumbar interbody fusion: comparison of two techniques. Chirurgia (Bucur) 109:812-821, 2014

42. Tormenti MJ, Maserati MB, Bonfield CM, Gerszten PC, Moossy JJ, Kanter AS, et al: Perioperative surgical complications of transforaminal lumbar interbody fusion: a singlecenter experience. J Neurosurg Spine 16:44-50, 2012
43. Wang JC, Bohlman HH, Riew KD: Dural tears secondary to operations on the lumbar spine. Management and results after a two-year-minimum follow-up of eighty-eight patients. J Bone Joint Surg Am 80:1728-1732, 1998

44. Wong AP, Shih P, Smith TR, Slimack NP, Dahdaleh NS, Aoun SG, et al: Comparison of symptomatic cerebral spinal fluid leak between patients undergoing minimally invasive versus open lumbar foraminotomy, discectomy, or laminectomy. World Neurosurg 81:634-640, 2014

45. Yoshihara H, Yoneoka D: National trends in the surgical treatment for lumbar degenerative disc disease: United States, 2000 to 2009. Spine J 15:265-271, 2015

46. Zhang Q, Yuan Z, Zhou M, Liu H, Xu Y, Ren Y: A comparison of posterior lumbar interbody fusion and transforaminal lumbar interbody fusion: a literature review and meta-analysis. BMC Musculoskelet Disord 15:367, 2014

\section{Disclosure}

Dr. Arnold is a consultant for Medtronic Sofamor Danek, FzioMed, SpineGuard, and Stryker Spine; owns stock in Z-Plasty; and has received reimbursed travel expenses from Stryker Spine and AOSpine. Dr. Darden is a consultant for Stryker, 4Web, and SpineGuard; owns stock in BioMedFlex; and has ownership in Stryker.

\section{Author Contributions}

Conception and design: Harrop, Ghobrial. Acquisition of data: Harrop, Ghobrial. Analysis and interpretation of data: Harrop, Ghobrial, Theofanis. Drafting the article: Ghobrial, Theofanis, Darden. Critically revising the article: Ghobrial, Darden, Arnold, Fehlings. Reviewed submitted version of manuscript: Harrop, Ghobrial. Statistical analysis: Ghobrial. Administrative/technical/ material support: Ghobrial. Study supervision: Ghobrial.

\section{Correspondence}

James S. Harrop, Department of Neurological Surgery, Thomas Jefferson University Hospital, 909 Walnut St., 3rd Fl., Philadelphia, PA 19107.email: james.harrop@jefferson.edu. 